J. Management and Humanity Research

Vol. 1, 2019, 37-44

ISSN: 2582-7766 (online)

Published on 18 June 2019

www.researchmathsci.org

DOI: http://dx.doi.org/10.22457/jmhr.v1a04104

Journal of

Management and

Humanity Research

\title{
Intervention Behaviors of Government on Technical Standard Alliance and Economic Outcomes
}

\author{
Xin Zhang ${ }^{1}$ and Wei $\mathrm{Li}^{2}$ \\ ${ }^{1}$ Chongqing Academy of Social Science \\ Chongqing - 400065, Chongqing, China. \\ ${ }^{2}$ School of Economics and Management \\ Chongqing University of Posts and Telecommunications \\ Chongqing - 400065, Chongqing, China. \\ Corresponding author: Xin Zhang, E-mail: 597025266@qq.com \\ Address: No. 270 Qiaobei Road, Jiangbei District, Chongqing, China, 400065 \\ Received 4 May 2019; accepted 10 June 2019 \\ Abstract. In this paper, the intervention behaviors of government on standard-setting \\ alliance and the corresponding outcomes are studied. In details, we formulate a game \\ model to describe and compare four types of popular intervention behaviors of \\ governments, which are no invention, invention on the establishment of alliance between \\ potential partners, providing subsidies on alliance's R\&D activity, and providing \\ subsidies on alliance's production activity. Two main findings are obtained. First, deep \\ interventions of government on partner relationships inside of the alliance are more \\ beneficial for standard establishments. Second, knowledge transfers among alliance \\ partners could contribute significantly to the acceleration and establishment of technical \\ standards. Therefore, government interventions on standard-setting alliance could be \\ effective if such behaviors could stimulate knowledge sharing between alliance members.
}

Keywords: technical standard; alliance; government interventions; subsidy policy

\section{AMS Mathematics Subject Classification (2010): 62P25}

\section{Introduction}

In network economy, technical standards have been playing a dominant role on the enterprise performance, the technology development and even the competency of a country. Technologies become standards by several different processes. A regulatory body with enforcement powers, a single dominant firm or a head-to-head competition among interested firms can impose a standard on a market (Shapiro, 2001; Lemley, 2002). However, it is increasingly common for firms to join together into one or more standard-setting alliances in order to develop standard technology and to sponsor adoption of a standard (Andrevski, et al., 2013; Aoki \& Nagaoka, 2004). The VHS alliance coordinated by Matsushita to sponsor a video recorder standard, the technical workstation alliance to develop and sponsor Unix operating system standards, the 3GPP alliance to develop the 3rd generation of wireless communications technology standard, and the Blu-ray Disk alliance leaded by Sony to sponsor a format standard are several 


\section{Xin Zhang and Wei Li}

examples of this phenomenon. These cases have illustrated that forming technical standard-setting alliance is of strategic value for a company or even a country to improve its competitive ability in the global economy (Keil, 2002; Lampe \& Moser, 2012). However, because of worries about knowledge spillovers, imitation or even exploitation (Das \& Teng, 2003), most enterprise are not willing to form technical standard alliance to develop core technologies collaboratively and to integrate related technologies to a package, even though their cooperation is of potential to make their new technology to a industrial standard (Hagedoorn, 2002; Hemphill, 2005). On behalf of national government, it hopes the local companies can conduct cooperation in R\&D actively and frequently so as to enhance the competency of technology and be more powerful in the worldwide competition. Therefore, governments are becoming more and more active to encourage and even intervene local enterprises to establish industrial alliance or technical standard alliance in recent years $(\mathrm{Li}, \& \mathrm{Li}, 2013)$.

Government intervention on alliances has been studied by some scholars from different perspectives. In fact, as the most well-known case in this area, the second generation mobile communication standard GSM gained great success in the world relying on the EU's efforts to coordinate relationships between partners and to promote the application of the unified standard in Europe (Glimstedt, 2001). Winn (2008) insisted that, although the EU's participation in GSM standard-setting alliance has achieved good benefits in short term, it seems to be less effective than the free econom model in long run, which has been proved in the United States. Thomberrry (2002) took the Japanese classic VLSI technology research group as an example to distinguish the significance of government participation. He found that the Japan government played an active role in this event by organizing the scientific research institutes and backbone enterprises who have competitive relationships with each other, and leading the formulation of R\&D alliance. Lopes de Souza and Lima de Souza (2009) showed that government departments play an important role in the process of setting standards for digital television in Brazil. Moreover, the specific roles of government in formulating and promoting national standards are further discussed. However, according to other relevant literatures on the behavior of government intervention, we know that there are a dozen of optional strategies for government to stimulate motivations of enterprises to participate in technical standard-setting alliances, such as by providing subsidies on R\&D or on production to firms (Sheng, 2008), to decrease the tax, to conduct government purchase to support company's innovating products, and so on.

However, in the existing research, few people have studied the choice mechanism of government intervention behaviors. In this paper, in order to fill this gap, all typical intervention behaviors of government will be distinguished, and the benefits generated by each behavior will be analyzed and compared based on a game model. As a result, we can indicate which behaviors are most advantageous to assist an alliance to build a technology standard.

\section{The model}

\subsection{Parameters}

In this paper, we assume an industry in which two oligopoly enterprises (enterprise 1 and enterprise 2) are competing. They are developing and producing homogeneous products in the market. Assuming that the market demand function satisfies a simple linear 
Intervention Behaviors of Government on Technical Standard Alliance and Economic Outcomes

relationship representing as $P=a-b Q$, where $P$ is the price of the product, $a$ is demand scale, and $Q=q_{1}+q_{2}$ is the total output for the entire industry in which $q_{1}$ and $q_{2}$ represents the product output of the enterprises 1 and 2, respectively. Furthermore, in order to simplify the computational work without any negative influence on the meaning and understanding of model results, we assume $b=1$. Since technological innovation can reduce the production cost, therefore, the final production cost of the two enterprises could be defined as $C_{1}=\left(A-x_{1}-k x_{2}\right) q_{1}$ and $C_{2}=\left(A-x_{2}-k x_{1}\right) q_{2}$, respectively, and $0<A<a$, where A represents the margin production cost, $x_{1}$ and $x_{2}$ represent the investment of technological innovation R\&D expenditures. Parameter $k$ is technology spillover between enterprise 1 and enterprise $2(0 \leq k \leq 1)$. In the case of $\mathrm{k}=0$, it means that enterprises could not obtain any technology spillover from each other. Production cost is reduced only by firm's own R\&D efforts. In the case of $k>0$, it indicates that the production cost of the enterprise is reduced by both these technology spillover and firm's own efforts.

\subsection{Modeling government behavior I : no intervention and no alliance between enterprises}

Without the intervention of government, competing enterprises do not establish any coalition relationship, independently carrying out $\mathrm{R} \& \mathrm{D}$ and production activities in the market. We assume that the two enterprises are trying to develop a same new technology with intention to build it as industrial standard. In such case, the influence of technology innovation on profit function is not affected by the other enterprise, which means no technology spillover happens between enterprises 1 and $2(\mathrm{k}=0)$. The profit functions of the two enterprises are as follows.

$$
\begin{aligned}
& \pi_{1}=\left(a-\left(q_{1}+q_{2}\right)-\left(A-x_{1}\right)\right) \times q_{1}-r x_{1}^{2} \\
& \pi_{2}=\left(a-\left(q_{1}+q_{2}\right)-\left(A-x_{2}\right)\right) \times q_{2}-r x_{2}^{2}
\end{aligned}
$$

In above profit functions, we assume that total cost for R\&D behavior of two companies are $r x_{1}^{2}, r x_{2}^{2}$ respectively, where $r$ represents the R\&D efficiency generated by firm's proprietary technology or knowledge $(r>0)$.

The equilibrium result could be generated by using Cournot Competition solution method. The equilibrium total output would be

$$
Q_{1}=q_{1}^{*}+q_{2}^{*}=\frac{6}{9 r-2}(a-A)
$$

\subsection{Modeling government behavior II: coordinating and assisting the formulation of technical standards alliance}

For this type of intervention, governments play major role to provide a platform on which related enterprises have opportunities to sit together negotiating with each other and form an alliance with a common goal of establishing an industry technical standard. In such standard-setting alliance, partners make commitments to share each other's relevant resources and make effort to research and develop a new technical standard 


\section{Xin Zhang and Wei Li}

collaboratively. Government just plays a role as a coordinator until the formulation of alliance. Once the alliance is successfully built up, the government's intervention is finished. In order to avoid violating the Anti-Trust Law, we assume that enterprises cooperate with each other only in R\&D stage, without cooperation in production and marketing stage. Profit functions for enterprises are as follows.

$$
\begin{aligned}
& \pi_{1}=\left[(a-Q)-\left(A-x_{1}-k x_{2}\right)\right] * q_{1}-r x_{1}^{2} \\
& \pi_{2}=\left[(a-Q)-\left(A-x_{2}-k x_{1}\right)\right] * q_{2}-r x_{2}^{2} \\
& \hat{\pi}=\pi_{1}^{* *}+\pi_{2}^{* *}
\end{aligned}
$$

The equilibrium total outputs are as following.

$$
Q_{2}=\frac{6 r}{9 r-(k+1)^{2}}(a-A)
$$

\subsection{Modeling government behavior III: providing subsidies on R\&D process of} technical standards

For this type of intervention, $R \& D$ subsidy strategy would be hired by government by providing direct financial supports to the standard-setting alliance for its research and develop activities, so as to compensate enterprises and encourages them to be active in the new technology innovation process. R\&D subsidy $S$ is defined as a subsidies ratio of enterprise's R\&D investment $(0 \leq s \leq 1)$. In such case, the two oligopoly firms' profit functions are as follows.

$$
\begin{aligned}
& \pi_{1}=\left[(a-Q)-\left(A-x_{1}-k x_{2}\right)\right] * q_{1}-r x_{1}^{2}+s x_{1} \\
& \pi_{2}=\left[(a-Q)-\left(A-x_{2}-k x_{1}\right)\right] * q_{2}-r x_{2}^{2}+s x_{2} \\
& \tilde{\pi}=\pi_{1}^{* * *}+\pi_{2}^{* * *}
\end{aligned}
$$

The equilibrium total outputs are as following.

$$
Q_{3}=\frac{2}{3} \times \frac{9 r *(a-A)+4.5 s(k+1)}{9 r-(k+1)^{2}}
$$

2.5. Modeling government behavior IV: providing subsidies on production process of the technical standards

In this case, government will provide member enterprises with production or marketing supports, which is also the process of applying new-built technical standard so as to promote the market diffusion. We use production subsidy $m_{\text {to }}$ represent the production subsidy to each member enterprise whoa are executing production activity with new technical standard. Since member enterprises cooperate in R\&D stage but compete in production and marketing stage thus output quantity decisions will be made individually by each enterprise. Their profit functions are:

$$
\begin{aligned}
& \pi_{1}=\left[(a-Q)-\left(A-m-x_{1}-k x_{2}\right)\right] * q_{1}-r x_{1}^{2} \\
& \pi_{2}=\left[(a-Q)-\left(A-m-x_{2}-k x_{1}\right)\right] * q_{2}-r x_{2}^{2} \\
& \hat{\pi}=\pi_{1}^{* * * * *}+\pi_{2}^{* * * *}
\end{aligned}
$$


Intervention Behaviors of Government on Technical Standard Alliance and Economic Outcomes

The equilibrium total outputs are as following.

$$
Q_{4}=\frac{2}{3}(a-A+m) \times\left(\frac{9 r}{9 r-(k+1)^{2}}\right)
$$

\section{Economic outcomes Comparison between government interventions}

Based on the preceding analysis and results, we could conduct evaluation on the economic outcomes of government's intervention behaviors and try to detect which behavior is more advantageous to stimulate the successful establishment of a new technical standard.

\subsection{Comparison between government behavior I and II}

The equilibrium outputs for government behavior I and II are shown by functions (3) and (7).

Since $Q_{1}>0$ and $Q_{2}>0$ naturally, thus we can easily obtain that $r>4 / 9$ is always satisfied.

Calculating the difference between Q2 and Q1, we can have

$$
Q_{2}-Q_{1}=6(a-A) \frac{9 r^{2}-11 r+(k+1)^{2}}{\left[9 r-(k+1)^{2}\right] *(9 r-2)}
$$

Obviously, the sign of $Q_{2}-Q_{1}$ is finally determined by the sign of $E=9 r^{2}-11 r+(k+1)^{2}$. After discussing on this by dividing parameter $\mathrm{k}$ into three conditions, we find the following results.

Proposition 1. when any of the following conditions is satisfied, the result of $Q_{2}>Q_{1}$ could be reached.

(1) $r \in(4 / 9,+\infty)$ under the situation of $k \in[5 / 6,1]$;

$$
r \in(4 / 9,(11-\sqrt{(5-6 k)(17+6 k})) / 18)
$$

$$
r \in((11+\sqrt{(5-6 k)(17+6 k})) / 18,+\infty) \text { under the situation of } k \in(2 \sqrt{7} / 3-1,5 / 6) \text {; }
$$

(3) $r \in((11+\sqrt{(5-6 k)(17+6 k})) / 18,+\infty)$ under the situation of $k \in(0,2 \sqrt{7} / 3-1)$.

It means that the active behavior of government intervention on technical standard alliance formulation is more beneficial for new technical standard establishment than the situation that the government does not interfere at all. When opposite conditions satisfied, result of $Q_{2}<Q_{1}$ would be reached, which shows that the behavior of government's no intervention is more beneficial for technical standard establishment.

\subsection{Comparison between government intervention behavior II and III}




\section{Xin Zhang and Wei Li}

The equilibrium outputs for government intervention behavior II and III are shown by functions (7) and (11), we can calculate the difference between $Q_{2}$ and $Q_{3}$.

$$
Q_{2}-Q_{3}=-\frac{4.5 s(k+1)}{9 r-(k+1)^{2}}
$$

Since the denominator $9 r-(k+1)^{2}$ is strictly greater than zero, thus, it is to see that $Q_{3}-Q_{2} \geq 0$ always holds. It shows that the government behaviors III is more beneficial than behavior II for new technical standard's establishment. Therefore, the following proposition can be obtained:

Proposition 2. Compared with the intervention type IIin which government only leads the formulation of standard-setting alliance, government's intervention behavior III in which $R \& D$ subsidies on alliance is provided is more helpful to promote the diffusion and establishment of new technical standards.

\subsection{Comparison between government intervention behavior II and IV}

The equilibrium outputs for government intervention behavior II and IV are indicated by functions (7) and (15). Calculating the difference between them, we can have

$$
Q_{2}-Q_{4}=-\frac{6 r m}{9 r-(k+1)^{2}}
$$

Since $m>0, r>4 / 9$, and it is obviously $9 r-(k+1)^{2}$ is strictly greater than zero, therefore, the estimate $Q_{2}-Q_{4}<0$ always holds, which shows that the impact of the intervention behavior IV is stronger than behavior II in aspect of stimulating the diffusion of new-built technical standard. So the following result can be obtained.

Proposition 3. Compared with the intervention behavior Ilin which government only leads the formulation of Standard-setting Alliance, government intervention behavior IV in which subsidies on production is provided is more helpful to promote the establishment of new technical standard.

\subsection{Comparison between government intervention behavior III and IV}

The equilibrium outputs for government intervention behavior III and IV are shown by function (11) and (15). Obviously,

$$
Q_{3}-Q_{4}=\frac{3 s(k+1)-6 r m}{9 r-(k+1)^{2}}
$$

By easy calculation, we can obtain the following result.

Proposition 4. In the case of $\frac{s}{m} \geq \frac{2 r}{k+1}$, government intervention behaviorIII is more helpful to promote the establishment of technical standards, relative to intervention behavior IV. On the contrary, in case of $\frac{s}{m}<\frac{2 r}{k+1}$, government intervention behavior IV 
Intervention Behaviors of Government on Technical Standard Alliance and Economic Outcomes

is more beneficial for establishment of new technical standards, relative to intervention behavior III.

\section{Conclusion and implication}

In this paper, we focused on the interventions of government on standard-setting alliance, and the relevant influence on the establishment of new technical standard. Main findings revealed by our model are as follows.

First, between government intervention behavior I and II, II will be more effective than I to develop a new technical standard on conditions. Generally, if government could motivate alliance formulation and encourage partners to share knowledge actively, which is beneficial to increase knowledge spillovers between partners, its intervention behavior II could create more value for standard development.

Second, between government intervention behavior II and III, behavior III is always more effective than behavior II to promote the development and establishment of new technical standard through alliance.

Third, between government intervention behavior II and IV, behavior IV is always more effective than behavior II to promote the development and establishment of new technical standard through alliance.

Fourth, between government intervention behavior III and IV, the effectiveness depends on conditions. In particular, if government is more willing to support firm's R\&D activity rather than production activity, by providing larger number of subsidy capitals, the intervention behavior III will be more effective than IV. By contrast, if government is more interested in stages of production and market diffusion, the intervention behavior IV will be more advantageous.

\section{Acknowledgement}

This work is supported by The National Social Science Fund of China under Grant No.17CGL059.

\section{REFERENCES}

1. G.Andrevski, D.J.Brass and W.J.Ferrier, Alliance Portfolio Configurations and Competitive Action Frequency, Journal of Management, 8(2013) 1-27.

2. R.Aoki and S.Nagaoka, The consortium standard and patent pools, The Economic Review, 55(4)(2004) 345-356.

3. T.K.Das and B.S.Teng, Partner analysis and alliance performance, Scandinavian Journal of Management, 19(3)(2003) 279-308.

4. H.Glimstedt, Competitive dynamics of technological standardization: the case of third generation cellular communications, Industry and Innovation, 8(1)(2001) 49-78.

5. J.Hagedoorn, Inter-firm R\&D partnerships: an overview of major trends and patterns since 1960, Research policy, 31(4)(2002) 477-492.

6. T.A.Hemphill, Cooperative Strategy and Technology Standard-Setting: A Study of US Wireless Telecommunications Industry Standards Development, George Washington University, (2005).

7. T.Keil, De-facto standardization through alliances-lessons from Bluetooth, Telecommunications policy, 26(3)(2002) 205-213. 


\section{Xin Zhang and Wei Li}

8. R.Lampe and P.Moser, Patent pools: Licensing strategies in the absence of regulation, Advances in Strategic Management, 29(2012) 69-80.

9. M.A.Lemley, Intellectual property rights and standard-setting organizations, California Law Review, 20(3)(2002) 1889-1980.

10. W.Li and T.Li, The organization modes of Chinese standard-setting alliances: from the perspective of government intervention, Science \& Technology Progress and Policy, 30(8)(2013) 25-36.

11. T.Lopes de Souza Lima and R.S.de Souza, Building the Digital TV Standard: the Brazilian Experience, 2009 GLOBELICS Conference, (2009).

12. C.Shapiro, Navigating the patent thicket: Cross licenses, patent pools, and standard setting, Innovation Policy and the Economy, 1(2001) 119-150.

13. Y.Sheng, Innovation Subsidies or Product Subsidies: the Government Strategy Choice of Technical Alliance, Chinese Journal of Management Science,16(6)(2008) 22-34.

14. J.B.Thomberrry, Competition and Cooperation: A Comparative Analysis of SEMA TECH and the VLSIR Research Project, Enterprise and Society, 3(4)(2002) 657-686.

15. J.K.Winn, Globalization and standards: the logic of two-level games, Journal of Law and Policy for the Information Society, 5(2008) 185-198. 